\title{
IDENTIDADE, PERTENCIMENTO E SOCIABILIDADE NO ESPAÇO URBANO: OBSERVAÇÕES SOBRE A PERCEPÇÃO DOS USUÁRIOS DO BAIRRO CIDADE BAIXA EM PORTO ALEGRE
}

\author{
Michelle Nascimento da Silva ${ }^{1}$
}

\section{Introdução}

A presente investigação tem seu começo em um levantamento dos frequentadores e moradores, bem como da paisagem local e busca-se realizar um roteiro narrativo que contemple essa dirvesidade de usuários que ali transitam, de que maneira ocupam o lugar, os traços de sociabilidades, dos sentimentos de identidade e pertença que possuem do lugar.

Eckert e Rocha (2005: 33), ao discorrerem sobre o "antropólogo na figura do narrador", discutem a morte do narrador tradicional e a necessidade de o antropólogo tornar-se um novo tipo de narrador que pratique as artes de ouvir para recuperar a riqueza das experiências e das artes de dizer do outro no cotidiano das grandes metrópoles. A escolha pela narrativa, neste artigo, teve por objetivo seguir este entendimento.

A Cidade Baixa congrega diferentes grupos sociais e detém uma forma histórica específica relacionada à expansão populacional da cidade. Neste bairro, marcado pela diversidade, local de encontro de muitos grupos sociais e de construção de territorialidades, existe, em sua circunscrição, diferentes redes de relações em que seus frequentadores e moradores estão inseridos, construindo seu espaço social e produzindo significados.

Situado próximo ao Centro Histórico de Porto Alegre e pertencente à Macrozona 1- Cidade Radiocêntrica (PDDUA, 2002), o bairro Cidade Baixa sugere ser um espaço por onde é possível compreender os sentidos de pertencer a um determinado lugar (Koury, 2003), entender como os moradores desenvolvem esse sentimento. Entende-se e propõe-se mostrar a Cidade Baixa na condição de lugar no qual são visualizados os sentimentos identidade, pertencimento e sociabilidade.

\footnotetext{
${ }^{1}$ Universidade Federal do Rio Grande do Sul, Brasil.
} 


\section{A Cidade Baixa}

A Cidade Baixa é um importante bairro na formação da cidade de Porto Alegre, é um espaço bastante conhecido por seus frequentadores, inclusive percebido como um bairro de lazer noturno (Reckziegel, 2009). A Cidade baixa é um bairro de origem antiga na cidade, o qual já possuiu vários nomes associados ao seu território: Arraial da Baronesa, Emboscadas, Areal da Baronesa e Ilhota. De acordo com Franco (2000) a partir de 1825 este bairro começou e se estabelecer ao longo do caminho da Olaria e do caminho da Azenha. O local foi formado inicialmente por pessoas de poucas posses, imigrantes italianos e escravos libertos ou fugidos (Menegotto, 2001).

Segundo Fonseca (2006), apesar deste bairro ser antigo, ele ainda vem mantendo muitas de suas características iniciais. O bairro abriga e conserva, disseminados em importantes partes de sua extensão, exemplares significativos da sua formação. Tais como: Largo Zumbi do Palmares, Instituto Pão dos Pobres, o complexo habitacional "Lupicínio Rodrigues", o Solar Lopo Gonçalves, a Ponte de Pedra e a Travessa dos Venezianos.

Dentro da circuscrição deste bairro, existem 08 (oito) Áreas de Interesse Cultural (AIC)s, de acordo com o Plano Diretor de Porto Alegre (PDDUA, 2002). Tal evidência nos permite entender o sentimento de preservação da história do local, bem como o de valorização, através da manutenção de uma morfologia autêntica. Isto, de maneira que a paisagem e o ambiente continuem garantindo o sentido de pertencimento da população local.

O bairro em tela é habitado, predominantememte, pela classe média. Conforme informações encontradas no site oficial da Prefeitura de Porto Alegre, a Cidade Baixa foi criada pela Lei 2022 de 7 de dezembro de 1959, bem como teve seus limites modificados pela Lei 4685 de 21 de dezembro de 1979, possuindo uma população de 16.522 moradores e 7.821 domicílios em 2010. Atualmente, a grande quantidade de bares configura o bairro e, ainda, é conhecido por ser um local frequentado por boêmios (Fonseca, 2006).

A paisagem local é amplamente heterogênia no que diz respeito a suas construções. Nas palavras de Lay (1997):

(...) antigas residências convivem com os prédios altos. Há predominância de construções no alinhamento, bem como grades de segurança nos jardins, entradas dos prédios e janelas, definindo claramente os domínios público e o privado. Os 
diferentes estilos construtivos utilizados desde o início do século estão representados no bairro, embora existam zonas de concentração de uma determinada tipologia. Em alguns pontos, mesmo a substituição das construções antigas, em terrenos de testada estreita, manteve uma das caractetrística bairro: das casas de porta e janela (p. 344$345)$.

A Cidade Baixa é também um ponto de tráfego de veículos e de fluxo de pessoas que por ali transitam, ou ora embarcam ora desembarcam dos coletivos urbanos e táxis para fruirem o bairro e/ou realizarem alguma atividade específica (trabalhar, estudar, consumir, morar). Segundo Lay (1997):

\footnotetext{
O traçado viário apresenta uma hierarquia, determinada pelo fluxo de pedestre e veículos, assim como pela localização das atividades de comércio, serviços e lazer. As avenidas João Pessoa, Vanâncio Aires, Aureliano de Figueiredo Pinto, Loureiro da Silva e Praia de Belas destinam-se ao escoamento do tráfego pesado (p. 345).
}

Esta área da cidade apresenta sua movimentação econômica através de suas lojas, salões de beleza, floriculturas, tabacarias, livrarias, cafés, vídeo locadoras, academias de ginástica, pet shops, armzéns, açougues, supermercados, bares, casas noturnas, restaurantes, lanchonetes, sorveterias e prestadoras de serviços em geral. É um espaço urbano onde coexistem pedestres, ciclistas e veículos. É ainda um lugar com pequenas concentrações pontuais de pedintes, moradores de rua e vendedores ambulantes.

Segundo de Certeau (1998: 202), "espaço é um lugar praticado”, o espaço leva em consideração "vetores de direção, quantidades de velocidade e a variável do tempo" (p. 201-202). Neste sentido, esta parcela de território é caracterizada por suas diversas formas de ocupação e permanência, as quais partem de um fluxo de pessoas, a pé, em veículos ou coletivos urbanos, ou ainda, como lócus para fruição de lazer para os diversos tipos de moradores e frequentadores, para passear com animais de estimação e, à noite, lugar onde alguns boêmios escolhem para divertirem-se, bem como dormitório de alguns moradores de rua.

Atualmente, o bairro vem buscando retornar seu período de prestígio e reconhecimento por seu carnaval de rua. Com a proximidade do Carnaval, moradores e comerciantes do bairro vem retomando as tradicionais "folias de rua" por intermédio de seus oito blocos de rua. A partir da década de 70 , os blocos de rua foram perdendo espaço para os desfiles das grandes escolas de samba.

$\mathrm{O}$ bairro preenche e confere visibilidade às varias formas sócio-politico-culturais. O largo Zumbi dos Palmares, por exemplo, é palco de eventos políticos, feiras, 
exposições de carros antigos, encontro de ciclistas, apresentações de música e dança, bem como, recebe temporariamente as arquibancadas para o desfile de Sete de Setembro.

Como espaço que detém parte significativa da historia de Porto Alegre, apresentando diversos usos e formatações na contemporaneidade, bem como ao longo do tempo, a Cidade Baixa é uma parcela do território urbano portadora de memória e, também, um dos lugares mais pertinentes para o estudo sobre a relação entre os usuários e os bairros de relevância histórica e cultural em Porto Alegre.

Desloquei-me por diversas vezes pela circunscrição do bairro Cidade Baixa, reconstituindo todo o seu perímetro e observando as avenidas, ruas e travessas que o compõe. Essas caminhadas, realizadas em horários distintos do dia, tiveram por intuito saber sobre os sujeitos permanentes e transitórios, os quais utilizam ou transitam pelo bairro, e dialogar com algumas dessas pessoas que se locomovem em suas vias em horários deversos.

Para Michel de Certeau a cidade e suas diferentes interpretações são percebidas como uma linguagem textual que se dá na prática do caminhar nas ruas. Daí o mesmo afirmar que uma das formas de tentar perceber a cidade é caminhar por ela (Certeau, 1994). A retórica ambulante para Certeau é a adaptação lingüística e a caminhada do pedestre, é a adequação lingüística ao contexto espacial onde o caminhante se encontra. A maneira de fazer, nesse caso, seria o falar e caminhar. Certeau prega a análise das maneiras de apropriação do espaço, que corresponde à manipulação de elementos de uma ordem construtora, a transitoriedade e os arranjos lingüísticos feitos para isso.

Com esse entendimento, a trajetória percorrida que passo a narrar pretendeu capturar e seguir o movimento diversificado e as formas de apropriação desse espaço urbano, transitórias e permanentes, pelas pessoas que o frequentam ou moram e, também os motivos de frequentá-lo ou tê-lo escolhido para morar, o que viabilizou uma percepção de múltiplos olhares sobre o lugar observado, nos diferentes períodos de sua utilização pelos informantes que se dispuseram a estabelecer um diálogo com esta pesquisadora.

Os períodos de caminhada foram divididos em horários diversos. Consistiram em percursos efetuados pelos turnos da manhã, tarde, noite e madrugada. Durante o dia, observou-se a presença de pessoas locomovendo-se para irem estudar, trabalhar, realizar exercícios físicos, passer com animais de estimação, ir ao cinema, comprar, pagar 
contas, consumir bebidas e produtos alimentícios. No turno da noite, as observações centraram-se na identificação das maneiras que o espaço urbano é ocupado por migrantes de outros bairros e habitués (FONSECA, 2006), moradores, mendigos, ambulantes e transeuntes em geral. Desta forma, as jornadas se deram nos horários compreendidos entre $6 \mathrm{~h}$ às $12 \mathrm{~h}$; entre $12 \mathrm{~h}$ e $18 \mathrm{~h}$; $18 \mathrm{~h}$ e $24 \mathrm{~h}$, bem como das $24 \mathrm{~h}$ às $6 \mathrm{~h}$ da manhã.

Para melhor operacionalização das atividades observatórias, o bairro fora dividido em seis sub-áreas. Estas subdivisões foram alicerçadas na definição de seis sub-áreas do bairro Cidade Baixa, realizadas por Lay (1997). De acordo com a autora:

O bairro foi subdividido em seis sub-áreas selecionadas a partir de critérios préestabelecidos: 1) trechos de rua que apresentassem caracerísticas próprias, que configurassem os diferentes sub-setores do bairro; 2) estarem localizadas em pontos dispersos, para que se obtivesse uma amostragem de maior abrangência no bairro. (p. 347).

As subdivisões do bairro, segundo Lay (1997) são: 1) Rua Sofia Veloso; b) Rua João Alfredo; 3) Rua da República; 4) Lima e Silva; 5) Av. João Pessoa; e 6) Travessa dos Venezianos. A rua Sofia Veloso e Travessa dos Venezianos são espaços caracterizados por serem mais tranquilos no que se refere à circulação de pedestres e veículos. As ruas da República e Lima e Silva são onde existe movimentação mais acentuada tanto durante o dia quanto à noite. Por sua vez a rua João Alfredo, além da movimentação noturna nos finais de semana e feriados, apresenta, juntamente com a avenida João Pessoa, fluxo intenso de veículos em diversos horários do dia e da noite, uma vez que a primeira oferece acesso ao centro da cidade e a segunda, à todos os bairros localizdos na Zona Sul.

\section{Os usuários}

As relações de identidade e pertencimento ao lugar são desenvolvidas no processo de apropriação e territorialização do espaço. Isto se dá quando os sujeitos ultrapassam a necessidade da apropriação de um locus, ou seja, quando se desenvolvem, neste local, valores ligados aos seus sentimentos e à sua identidade cultural e simbólica, reformulando o espaço onde vive, ao qual se identificam e se sentem pertencer (Raffestin, 1993). 
Buscar a identidade e o sentimento de pertença de um lugar é procurar compreender o entrelaçar das falas e conceitos que dão forma aos espaços. Os significados, os sentidos e os valores atribuídos a um espaço, e que constituem sua identidade e pertencimento são elaborados e reelaborados a cada momento.

Segundo Simmel (2006: 60), “a sociação é a forma (que se realiza de inúmeras maneiras distintas) na qual os indivíduos, em razão de seus interesses - sensoriais, ideais, momentâneos, duradouros, conscientes, inconscientes, movidos pela causalidade ou teleologicamente determinados -, se desenvolvem conjuntamente em direção a uma unidade no seio da qual esses interesses se realizam".

A sociabilidade, para Simmel (2006: 82), é esse terreno em que os interesses humanos podem exprimir-se, em termos de cultura subjetiva, assumindo feições lúdicas, dramatúrgicas, proxêmicas e estilizantes da existência, permitindo ao indivíduo exprimir-se, mediante as práticas da conversação, da coqueteria, da sociabilidade do salão, das exposições, etc. de forma diversificada e escapar à interação homogênea com os outros (p. 70), trazendo ao indivíduo "um sentimento de libertação e alívio"

A sociabilidade é um tipo de sociação que não contém qualquer finalidade externa a ele e que é valorizado em si mesmo, isto é, os indivíduos se associam, pois valorizam o fato de estarem juntos, embora esse "estar junto" se dê de várias formas. Dessarte, a sociabilidade é valorizada em si mesma, é a forma lúdica de sociação, porque é propriamente a forma pela qual as pessoas apreciam a mútua companhia entre elas, a forma do relacionamento sociável, do entretenimento.

A Cidade Baixa é uma paisagem preenchida por diversos arquétipos humanos que ocupam de maneiras variadas e em períodos diversificados, ali passeiam, trafegam, trabalham, estudam, divertem-se, moram, ou até mesmo praticam a mendicância.

São os moradores locais que, costumeiramente, realizam caminhadas matinais, passeiam com seus animais de estimação e praticam o ciclismo. Alguns idosos colocam suas cadeiras na calçada e sentam, ou ainda, debruçam-se nas janelas, para apreciar o bairro e tomar chimarrão. As crianças são conduzidas por seus pais ou responsáveis até as creches do bairro, ou ainda, os estudantes do nível fundamental, acompanhados ou não, ingressam nas escolas para mais um dia de aula. Já os demais estudantes de ensino médio ou universitário, deslocam-se para seus respectivos estabelecimentos educacionais, os quais estão localizados nos bairros adjacentes a seu bairro. Conta-se, ainda, com a presença dos boêmios a partir do horário vespertino, taxistas, policiais, 
alguns guardadores de carros e vendedores ambulantes, comerciantes, jovens, crianças de rua, pedintes e turistas.

Esta parcela do território também convive com a coexistência de espaços construídos que são utilizados para fins religiosos. Os quais representam as orientações católica, batista, budista, seicho-no-ie, espírita, maçônica, bem como as religiões de matriz africana.

O bairro nos turnos da manhã (6h às $12 \mathrm{~h}$ ) e tarde (12h às $18 \mathrm{~h}$ ) é um ambiente medianamente intenso e tranquilo. Ao passo que as ruas João Pessoa, Lima e Silva e João Alfredo possuem uma movimentação significativa de veículos; as ruas da República, Sofia Veloso e Travessa dos Venezianos, são mais pacatas. À noite (18h às 24h) e na madrugada ( $24 \mathrm{~h}$ às $6 \mathrm{~h}$ ), normalmete de quinta-feira à domingo ou nas vésperas de feriado, o bairro costuma atrair uma grande quantidade de pessoas de diversos estilos. Os tipos que transitam pelo bairro mudam conforme o dia da semana e o turno. Os bares ficam abertos até depois da meia-noite, viabilizando o acolhimento de pessoas que saem de sua jornada de trabalho e prolongam sua permanência, ou ainda, deslocam-se de outros bairros para fruirem o local até às $21 \mathrm{~h}$, de segunda à quinta-feira, e até 22 e 24 h na sexta-feira. Lembrando, também que os usuários de lazer noturno aparecem mais expressivamente a partir da quinta-feira, em que muitos atravessam a madrugada, deixando o bairro entre $4 \mathrm{~h}$ e $5 \mathrm{~h}$, e outros, que permanecem, principalmente nos finais de semana, até as $6 \mathrm{~h}$, ou ainda, até as $7 \mathrm{~h}$. Durante os dias úteis, entre as $17 \mathrm{~h}$ e 20h, é possível visualizar o regresso dos moradores do bairro para suas residências após sua jornada de trabalho ou estudos.

Outros frequientadores iniciam a utilização do espaço a partir das $22 \mathrm{~h}$ aproximadamente, e em certos horários de forma simultânea. Migrantes de outros bairros e habitués (Fonseca, 2006) que usufruem o lazer noturno durante toda a noite, taxistas, vendedores ambulantes, e moradores de rua que perambulam e/ou dormem nas calçadas menos movimentadas passam a compor o novo cenário ao ambiente e um outro modo de apropriação do lugar.

O policiamento militar e as fiscalizações municipais de trânsito (EPTC), indústria e comércio (SMIC), saúde (SMS) e limpeza urbana (DMLU) entram em cena nos dias mais movimentados a partir das $23 \mathrm{~h}$ e permanecem até entorno das $4 \mathrm{~h}$, esse conjunto de ações é popularmente conhecido como “Operação Sossego". O bairro ganha uma nova roupagem para os usuários da noite, com a coexistência de diversas tribos urbanas, que 
o diferencia, bem como importuna o morador da Cidade Baixa que, após a jornada do dia, buscam tranqüilidade para dormir em suas residências.

Nos finais de semana, a ocupação diurna do bairro se diferencia. $\mathrm{O}$ bairro passa a ter movimentação mais intensa a partir das $12 \mathrm{~h}$ e 30min (horário que os moradores e, também visitantes iniciam seu período de almoço). Já nos feriados, a circulação é bem mais reduzida.

O bairro é, então, ocupado por ciclistas, moradores em suas caminhadas matinais e de final de tarde e turistas, principalmente os que embarcam na linha turística que parte do bairro e percorre os outros pontos turísticos da cidade. A agitação, o trânsito e os pedestres diminuem. À noite, o lazer noturno ganha espaço e a freqüência de boêmios aumenta.

A partir das 20h, nos domingos, a rua Lima e Silva é tradicionalmente ocupada por jovens e adolescentes que escolhem a frente de um supermercado para cultivar sua sociabilidade. Estes consistem em grupos que se encontram sempre aos domingos para ocuparem o espaço em tela. Tal conglomeração gera antipatia e desconforto aos moradores do bairro, os quais se sentem inibidos com a presença dessas pessoas. Este trecho da rua, neste período, adquire linguagem e estética próprias, que a diferencia e abespinham os demais usuários do bairro. Isto pode ser mais bem depreendido em declaração feita por um morador em conversa informal:

O supermercado passou a fechar mais cedo nos domingos por causa desse 'povinho' que vem para cá. Um 'povinho' estranho que fica bebendo vinho e cachaça pelas calçadas, ficam fazendo muita algazarra e atrapalhando a circulação das pessoas.

Ao longo das minhas caminhadas durante a semana e finais de semana, estabeleci diálogo com alguns turistas encantados pelo espaço urbano do bairro, e da conveniência de ter adicionado este local em seus roteiros turísticos. Turistas de vários estados do Brasil, bem como de outros países, principalmente no início da manhã e nos finais de tarde, vêm ao bairro para realizarem passeios nos ônibus de turismo da prefeitura. Estes, por sua vêz, aproveitam o contato com o bairro para conhecê-lo melhor. É possível perceber o encantamento com o local através do que demonstra uma turista em sua fala:

Poderia pensar, por um instante, que estava na Europa! Algumas ruas, casas e cafés me lembram um pedacinho da França. 
É curioso notar que mesmo os usuários que passaram a freqüentar a pouco tempo o bairro apontam o bairro como um ponto de encontro e lazer noturno na cidade. Muitos dos que circulam durante a semana, ou mesmo nos finais de semana, no bairro, realizam suas refeições nos restaurantes e lancherias espalhadas pelas ruas locais e "bebem uma cerveja com amigos" e familiares, ou marcam encontro tendo por ponto de referência alguns locais específicos.

A Cidade Baixa dispõem de muitos locais de referência. Os mais recordados nas conversas informais foram: o Centro Comercial Nova Olaria, o Cine Guion Center, o Colégio Pão dos Pobres, Largo Zumbi dos Palmares, a Igreja Sagrada Família, o supermercado Zaffari, o restaurante Copacabana, o Centro Cultural Studio Clio, o Bar Opinião, o Museu Joaquim José Felizardo, o Teatro de Câmara Túlio Piva e a Travessa dos Venezianos. Desta maneira, para os usuários, estes locais são pontos de referência ‘do bairro e no bairro', são alguns símbolos urbanos locais.

\section{A sensação de (não) pertencimento e identidade local}

É válido recordar, todavia, que para o conjunto dos usuários, a Cidade Baixa simboliza também um marco importante de reconhecimento de Porto Alegre. Quando se questionava sobre os pontos do bairro que melhor representam a Cidade, os mais lembrados foram os pontos que faziam referência aos aspectos históricos, culturais e de lazer. Para Ariel Gravano (2003), o bairro é pensado na esfera das significações, práticas e discursos. Ele sugere o estudo do bairro enquanto espaço simbólico e ideológico, o qual adquire e constrói valores, bem como identidades sociais urbanas, que são atribuídas pelos indivíduos.

O bairro é um tradicional reduto boêmio da cidade, como muitos afirmam, embalados pelos referenciais históricos e de tradição cultural, manifestados em diversos materiais de publicidade turística sobre a capital, a Cidade Baixa é igualmente sinônimo de afeição e desafeto. $\mathrm{O}$ desafeto se refere, entre outros fatores, às novas intervenções no bairro, por exemplo, pode-se citar a construção de um prédio com cerca de 20 andares que alterou a paisagem característica do bairro e a luta pela manutenção do seu traçado e estrutura ambiental, mesmo possuindo Áreas de Interresse Cultural (AIC) elencadas no Plano Diretor Municipal (PDDUA, 1999). 
Refere-se ainda à poluição sonora produzida à noite pelos bares e frequentadores do bairro, com o aumento da intensidade do trânsito no local, bem como o surgimento de discretos pontos de tráfico de drogas, ou por ter seu bairro se tornando alvo de violência e ação de pequenos delitos. Refere-se também ao estranhamento que sentem quando vêem o bairro sendo utilizado por pessoas ou grupos que parecem não se reconhecer. Em decorrência do anonimato da multidão que vaga pelas calçadas.

Alguns informantes falaram, também, evitar algumas áreas do bairro devido ao sentimento de insegurança provocado no indivíduo. A insegurança reflete-se em um plano moral, pela presença noturna e diurna, embora de uma forma menos visível, do uso de drogas por jovens e adolescentes no local, como também na esfera espacial, onde busca-se fortalecer o uso das ciclovias. A insegurança ainda se reflete nas pessoas que, em estado de embriaguês ou drogadição, provocam brigas e desordem, que incomodam e assombram a população que passa ou permanece durante a madrugada no bairro.

O desafeto em relação ao lugar também está vinculado ao princípio de decadência de setores do bairro situados na rua João Alfredo, na rua da República (trecho entre as ruas Borges de Medeiros e João Alfredo), bem como na avenida Loureiro da Silva. Estes locais são caracterizados por possuírem equipamentos urbanos sem manutenção, e, ainda, pela sujeira e pelo odor de urina no lugar. Os usuários associam o desafeto, também, ao público que a frequenta, associado quase sempre a pessoas consideradas marginais e vagabundos.

É dígno de atenção que, mesmo que vários informantes confirmem transitar pelo bairro uma ou mais vezes ao dia, mais especificamente nos locais referidos como objeto de desafeto, alegam que permanecem no local apenas o tempo suficiente para a realização de uma determinada atividade ou "estão só passando". Dissociado-se, desta forma, o estar lá do se manter permanentemente lá, e assim colocam um distanciamento entre si e os freqüentadores que ali permanecem. No estranhamento e na separação, podem colocar-se fora e apontar esse setor específico do bairro como um lugar inseguro e desagradável por causa de quem o frequenta. Afirmam que os que frequentam são os outros, imputam a esses outros uma parte da decadência do perímetro em tela e responsabilizam a administração municipal por não realizarem ações eficazes no âmbito da segurança e disciplinamento do lugar.

O bairro Cidade Baixa, entretanto, é um local onde as intensões de afeto e de apego ao lugar e à cidade se estabelecem. Sua referência conota um aspecto importante 
de um sentimento de pertencer ao bairro, de ter em si o lugar. A Cidade baixa é percebida pela maioria dos informantes como reduto da boemia e portador de grande parte da história de formação da cidade de Porto Alegre. Um espaço de relevância histórica que marca e dá identidade ao bairro e, por extensão, aos seus moradores.

A Cidade Baixa é narrada, a partir de então, por intermédio de um viés afetuoso que reflete a cidade e o bairro. A atualidade, através do tempo, identifica e comporta diversas formas de usos, contornos e valorações, e esta parcela do território urbano torna-se um espaço de memórias. O que acaba por elencar os diversos usos do espaço e os contornos de sua ocupação, bem como a inter-relação entre freqüentadores e moradores e, por extensão, suas redes de relações sociais. Os informantes, por sua vez, identificam e narram o lugar de uma maneira e de um jeito singulares, que qualificam sua individualidade enquanto cidadãos e simultaneamente revelam o hábito, a tradição e o costume que os consagram membros de uma totalidade.

Para Petersen (1994), existe máxima aproximação entre espaço e tempo na inserção dos hábitos de vida na cena da rua, do bairro. De acordo com essa autora, o tempo determina a sedimentação necessária das relaçoes sociais e do cenário, isto é, da integração entre os atores do cotidiano e da apropriação das imagens ao seu redor. No próprio conceito de bairro, Pierre Mayol observa estar contida essa noção de identidade, uma vez que:

(...) é um domínio do ambiente social, pois ele constitui para o usuário uma parcela conhecida do espaço urbano na qual, positiva ou negativamente, ele se sente reconhecido" (1996: 40).

Mayol (1996) refere-se ao bairro como o lugar pelo qual o morador se apropria quando trasgride o âmbito privado residencial. O mesmo se dá, segundo ele, "mediante a repetição do engajamento do corpo do usuário no espaço público” (p. 42). O autor ainda conceitua o que chama de 'prática cultural', ela vem a ser o

sistema de valores subjacentes que estruturam as tomadas de atitudes fundamentais da vida cotidiana, que passam despercebidos à conciência dos sujeitos, mas são decisivos para sua identidade individual e de grupo (p. 43).

O sentimento de pertencimento está relacionado à aproximação, bem como da ligação com o local. É uma idéia de enraizamento, em que o indivíduo constrói e é construído, planeja e se sente parte de um projeto, modifica e é por ele modificado. 
Como declarou um dos informantes sobre a Cidade Baixa e por extensão sobre a cidade de Porto Alegre:

Tem horas que eu paro para pensar de um jeito que me permite fazer um discurso sobre cada esquina daqui. Ao longo desses meus oitenta e poucos anos de existência, pude servir de testemunha de grande parte das mudanças de Porto Alegre. Eu recordo, por exemplo, quando eu era guria nova ainda, lembro que eu levava meu filho, pequenininho, de três para quatro aninhos só, foi por volta de cinqüenta e cinco... isso... eu caminhava com ele pela Travessa dos Venezianos, almoçávamos por ali e depois íamos caminhando até a Redenção. Aí, lá ele se soltava a brincar. Eu vi essa cidade crescendo, o bairro evoluindo

E continua:

A Cidade Baixa, a pesar dos pesares, sempre foi um lugar bom de viver. Eu sempre gostei de morar aqui. $\mathrm{O}$ que eu não queria que acontecesse era que essas casas antigas fossem desmanchadas e que colocassem aqueles prédios enormes que sufocam a gente. Eu vejo aqui dessa forma. Eu faço parte do bairro e o bairro faz parte de mim

O sentimento de fazer parte, de pertencer, nesse entendimento, transcende os obstáculos da insatisfação. As críticas ao lugar possuem uma conotação de desejar o melhor, de intervir positivamente no sentido de corrigir os aspectos negativos da Cidade Baixa que traz consigo na memória.

Há uma relação significativa entre a construção da memória e a construção da identidade. Sinteticamente, a memória legitima a identidade. Ela é um referencial que norteia a construção de identidades. Segundo Pollak (1992: 204), a memória é um elemento constituinte do sentimento de identidade, "na medida em que ela é também um fator importante do sentimento de continuidade e de coerência do grupo em sua reconstrução em si”.

Por sua vez, Halbwachs traz uma importante contribuição para a discussão das identidades territoriais, pois enfatiza a relação entre memória e lugar: "não há memória coletiva que não se desenvolva num quadro espacial" (1990: 143). E ainda, por enfatizar a existência de um dinamismo nas memórias coletivas. Elas estão sempre se modificando e se definindo. Transformando-se de acordo com a inserção dos indivíduos com outros grupos sociais.

Já Pollak (1992) contribui significativamente quando fala sobre a relação entre identidade e memória, na qual se destacam as fronteiras de pertencimento e o 
sentimento de coerência, indicando três elementos constitutivos da identidade: os "acontecimentos", as "pessoas e personagens" e os "lugares" da memória.

Os mais velhos apropriam-se do lugar para reencontrar ou fazer novos amigos, recordar, passearem ou fazeres pequenas compras. Este público não reside nescessariamente no bairro há 30 anos ou mais (o que não vem a ser recorrente), mas sim há 15 ou 17 anos. Nas suas recordações tendem a comparar e temem não ver mais o bairro de suas memórias, de suas experiências do passado. Receiam ter que testemunhar a tradição e a história do bairro sendo apagada pela inovação. Eles percebem as novas intervenções com desconfiança, por não reconhecerem nelas o cerne essencial das tradições que alicerçaram suas vidas até então.

Em seu trabalho sobre a memória de velhos moradores de São Paulo, Ecléa Bosi (1992) constata que os caminhos percorridos pelos moradores do bairro, e seus marcos de orientação no espaço, estão eivados de significados. "O bairro é uma totalidade estruturada, comum a todos, que se vai percebendo pouco a pouco, e que nos faz um sentido de identidade" (p. 147). Para a autora, esse espaço urbano é um

(...) lugar nosso, e um lugar nosso deve ter (...) fechamento e proximidade de elementos, deve ser mais denso que seu entorno e permitir a dialética da partida e do retorno (1992: 147).

As considerações sobre o bairro, assim, ecoam com a combinação de estima e preocupação. E, também como um conhecimento constantemente apto a ser narrado para quem desejar escutar. Os mais jovens também demonstram apreço pelo bairro e entendem o lugar como placo para namoros, passeios, lazer e diversão.

As áreas de lazer são, predominantemente, nas ruas Lima e Silva e República, seus bares, pubs, o Centro Comercial Nova Olaria, o Cine Guion Center (a rua João Alfredo se caracteriza mais pelo lazer noturno especificamente). Entretanto, ao discorrerem sobre a relevância da Cidade Baixa para a cidade de Porto Alegre, reportam-se sempre aos aspectos boêmios, históricos, culturais e turísticos locais com um tom de afeição pelo bairro, onde gostariam de ver ressaltada e confirmada a devida importância que tem na cidade.

Os comerciantes do bairro falam da importância da Cidade Baixa para o município e para o comércio local. Observam, porém, a necessidade de reforçar a identidade do bairro. Os estabelecimentos comerciais de lazer noturno são alvo de reclamações dos moradores, sendo responsabilizados pela poluição sonora, insegurança 
e a sujeira dos espaços. Estabelecendo-se visivelmente um conflito entre proprietários de bares e moradores nesse sentido.

A Prefeitura Municipal, com o objetivo de conciliar as necessidades dos moradores, comerciantes e freqüentadores da noite na Cidade Baixa, realiza a denominada "Operação Sossego", na qual fiscaliza os horários de funcionamento dos estabelecimentos, bem como sua adequação quanto aos dispositivos que reduzam a poluição sonora. Ainda, o governo municipal criou um Grupo de Trabalho (GT) para tratar especificamente das questões a serem melhoradas no bairro.

Já os comerciantes locais constituíram um grupo próprio para promover a valorização do bairro chamado de "Cidade Baixa em Alta". Pode-se depreender melhor a sua finalidade pelo conteúdo divulgado em seu site na internet, que informa o seguinte:

(...) temos como objetivo trazer de volta ao bairro toda cultura, entretenimento, música e diversão. Somente a Cidade Baixa, com sua cena eclética, pode proporcionar isso para Porto Alegre. (...) Queremos uma Cidade Baixa melhor, diversas iniciativas serão desenvolvidas no bairro. Contamos com sua ajuda para compartilhar essa ideia e transformar a Cidade Baixa em um bairro de muita cultura, diversão e educação entre moradores, frequentadores e comerciantes.

Quando perguntei a um morador do bairro sobre os problemas da Cidade Baixa ele informou que em relação à violência o local não é um dos mais perigosos da cidade, mesmo sendo alguns setores sendo temido pelas pessoas que o utilizam. Deduz que os receios das pessoas são motivados pela permanência de moradores de rua em estado de embriaguês e/ou drogadição, bem como de alguns frequentadores, pois os mesmos têm comportamentos desagradáveis. Conta que fora os casos de agressões, desordem e bebedeiras, o bairro não contém focos de grande violência.

Para o morador, os casos que merecem mais atenção são os grupos de pessoas que "fumam maconha", na maioria dos casos, representados por jovens de ambos os sexos, os quais agem naturalmente nas calçadas. Segundo o morador, o que mais gera incomodo é o fato de que essas pessoas, juntamente com os alcoolizados, terem o hábito inconveniente de urinar e/ou vomitar nas calçadas, árvores, portões das casas e edifícios. Isso consequentemente provoca o mau cheiro em certos pontos do bairro. Neste sentido, este informante, morador da rua João Alfredo, conta um episódio a respeito dessa situação: 
Uma vez eu fui numa reunião de condomínio e comentei que sempre que eu abria minha janela de manhã sentia um cheiro muito forte e perguntei o que era... Imediatamente, uma senhora de idade que morava há bastante tempo ali, disse indignada: '(...)- Aquilo ali é mijo! É mijo, vizinho! O pessoal enche a cara e depois vem fazer nosso portão de banheiro!'(...). Eu fiquei chocado.

$\mathrm{Na}$ exposição feita pelo morador, desta forma, a Cidade Baixa é vivenciada e lida através da memória afetiva, de um lugar que faz parte de sua própria história de vida. É através dessas imagens que se revela o bairro como lugar de identificação de laços pessoais com outros usuários, e lugar também de tipologia e identidade de pessoas e grupos sob a ótica da segurança local.

Assim que o dia começa tomar o lugar da madrugada, os usuários noturnos cedem lugar para mais uma manhã de caminhadas pelas ruas do bairro, de idas para o trabalho, para compras ou estudo, passeios com animais de estimação, para os idosos se porem a observar o movimento, para a chegada das crianças nas creches, para os veículos que se deslocam para o Centro Histórico, até atingir ápice e depois findar ao vespertino, quando mais um período noturno de avizinha.

\section{Considerações Finais}

O bairro Cidade Baixa, como se pode constatar até o momento através das descrições, é marcado por uma heterogeneidade dos seus atores, é um lugar múltiplo de onde se capta boa parte da cidade. A movimentação que propulsiona o bairro, desta forma, é constituída por múltiplos usos que perpetram o local no seu dia-a-dia. Maneiras de apropriação do espaço urbano que vão constituíndo eixos de construção simbólica e verdadeira a cerca do lugar e sua significação para a cidade, bem como para a vida de todos que nela habitam. Tais eixos acabam por compor um esquema simbólico, de relações complexas, repleto de sentimentos positivos e negativos, preocupações e indiferenças, pessoas que se entem parte do espaço do bairro e outras que se sentem à parte.

Múltiplas formas relacionais, nem sempre contraditórias entre si, mas predominantemente antagônicas, guiam os sentidos e os valores dos usuários com a Cidade Baixa. Supre o significado do afeiçoar-se ao lugar, de consolidar o bairro que desejam ter, seus sentimentos de desafeto devido ao perecimento a que determinados setores locais correm o risco de experimentar. Independente dos aspectos negativos 
virem à tona, o bairro está presente na memória dos moradores e frequentadores, bem como lhes confere uma identificação e sentimento de pertencer a esse espaço urbano.

As identidades surgem a partir de um processo de apropriação dos usuários pelo espaço, onde o mesmo estabelece uma relação de identidade e pertencimento tanto concreta quanto subjetivamente com o espaço criado por e para si. Em síntese, o indivíduo constrói espaços para si, concreta e/ou subjetivamente, e estabelece relações de pertenciento e identificação, bem como exerce sua sociabilidade.

\section{Referências}

CERTEAU, Michel de. A invenção do cotidiano. 2. ed. Petrópolis : Vozes, V.1. artes de fazer. 1996.

FONSECA, Luciana Marson. Dois rumos na noite de Porto Alegre : dinâmica socioespacial e lazer noturno nos bairros Cidade Baixa e Moinhos de Vento. Dissertação de Mestrado. PROPUR, UFRGS. Porto Alegre, 2006.

FRANCO, Sérgio da Costa. Gente e Espaços de Porto Alegre. Porto alegre, $2^{\mathrm{a}}$ Ed. Editora da Universidade, 156p. 2000.

GRAVANO, Ariel. Antropología de lo barrial. Ed. Espacio, Buenos Aires, 2003.

HALBWCAHS, Maurice. Memória Coletiva. São Paulo: Centauro, 2006.

KOURY, Mauro Guilherme Pinheiro. O local enquanto elemento intrínseco da pertença. In: Cláudia Leitão (Org.). Gestão cultural: significados e dilemas da contemporaneidade. Fortaleza: Banco do Nordeste, 2003.

LAY, Maria Cristina Dias et. al. Percepção da estrutura e desempenho de um setor urbano : bairro cidade baixa, Porto Alegre - RS. In: Encontro Nacional da Anpur (1997: 7 Recife). Anais : vii encontro nacional da anpur : novos recortes territoriais, novos sujeitos sociais: desafios ao planejamento. Recife : UFPE, Anpur, vol.1, p.341-362. 1997.

MAYOL, P. Morar. In: CERTEAU, M; GIARD, L; MAYOL, P. A invenção do cotidiano: 2. morar, cozinhar. Trad. Ephraim F. Alves e Lucia E. Orth. Petrópolis: Vozes, 1996.

MENEGOTTO, Renato. Cidade Baixa: pela manutenção dos cenários de um bairro tradicional de Porto Alegre. Dissertação de Mestrado. PPG de História, PUCRS. Porto Alegre, 2001.

PETERSEN, Sílvia Regina Ferraz. A renovação da historiografia e o tema da vida cotidiana: desfazendo alguns equívocos. In: Porto Alegre na virada do seculo 19 : cultura e sociedade. Porto Alegre : Ed. da UFRGS,.p. 112-125. 1994. 
POLLAK, M. Memória e identidade social. Estudos Históricos, Rio de Janeiro, v.5, n.10, p.200212: 1992.

PORTO ALEGRE. Prefeitura Municipal. Secretaria do Planejamento Municipal. Plano Diretor de Desenvolvimento Urbano Ambiental - 2. PDDUA : PDDUA lei comentada. Porto Alegre : PMPA, 19 f.: il., mapas, plantas, fots. 2002.

RAFFESTIN, Claude. Por uma Geografia do poder. São Paulo: Ática, 1993.

RAFFESTIN, Claude. Por uma geografia do poder. Tradução de Maria Cecilia França. São Paulo: Ática, 1993.

RECKZIEGEL, Daniela. Lazer noturno: aspectos configuracionais e formais e sua relação com a satisfação e preferência dos usuários. 2009.

ECKERT, Cornelia e ROCHA, Ana Luiza C. da. O tempo e a cidade. Porto Alegre: Editora da Universidade/UFRGS, 2005.

SIMMEL, George. Questões fundamentais da sociologia. RJ, Jorge Zahar, 2006.

\section{Sites consultados}

http://www2.portoalegre.rs.gov.br, Prefeitura Municipal de Porto Alegre, último acesso em 12/2012.

http://cidadebaixaemalta.com.br, Cidade Baixa em Alta, último acesso em 01/2013.

http://ong.portoweb.com.br/cidadebaixa, Associação Comunitaria dos Moradores da Cidade Baixa, último acesso em 12/2012.

Recebido em: 09/08/2013

Aprovado em: 12/09/2013 